\title{
A VULNERABILIDADE AGRAVADA DA CONSUMIDORA GESTANTE, $O$ ASSÉDIO DE CONSUMO E O DEVER DE INFORMAÇÃO DO ESTADO E DOS FORNECEDORES
}

\section{THE AGGRAVATED VULNERABILITY OF THE PREGNANT CONSUMER, THE HARASSMENT TO THE CONSUMER AND THE DUTY OF STATE AND SUPPLIER INFORMATION}

\author{
Luiza Tuma da Ponte Silva* \\ Isabelle de Assunção Rodrigues ${ }^{2 *}$
}

\section{RESUMO}

O objetivo do artigo é demonstrar que o contexto hipermoderno, caracterizado pelo assédio de consumo, fomenta práticas de consumo que agravam a vulnerabilidade das consumidoras gestantes, as quais, a partir de diferentes análises, são consideradas hipervulneráveis. Metodologicamente, a pesquisa é, quanto aos objetivos, exploratória e de abordagem qualitativa, tendo como procedimento o levantamento bibliográfico. Uma das principais conclusões é que o Estado e os fornecedores devem agir de forma proativa, promovendo o dever de informação aos consumidores, especialmente às gestantes, para que estas consigam obter emancipação no mercado de consumo.

Palavras-Chave: Assédio de Consumo; Gestantes; Hipervulnerabilidade; Dever de Informação; Estado; Fornecedores.

\begin{abstract}
The objective of this article is to demonstrate that the hypermodern context, characterized by consumer harassment, promotes consumption practices that exacerbate the vulnerability of pregnant consumers, who, from different analyzes, are considered hypervulnerable. Methodologically, the research is, in terms of objectives, exploratory and with a qualitative approach, using bibliographic survey as a procedure. One of the main conclusions is that the State and suppliers must act proactively, promoting the duty of information to consumers, especially pregnant women, so that they are able to achieve emancipation in the consumer market.
\end{abstract}

\footnotetext{
${ }^{1}$ Mestranda pelo Programa de Pós-Graduação em Direito, Políticas Públicas e Desenvolvimento Regional no Centro Universitário do Pará (PPGD/CESUPA). Especialista em Direito Constitucional pela Pontifícia Universidade Católica de São Paulo (PUC-SP). Graduada em Direito pelo Centro Universitário do Estado do Pará (CESUPA). Advogada. Email: luizatuma@ hotmail.com. Orcid: https://orcid.org/0000-0002-4833-9797

${ }^{2}$ Mestranda pelo Programa de Pós-graduação em Direito da Universidade Federal do Pará (PPGD/UFPA). Bolsista CAPES - Código de Financiamento 001. Especialista em Direito Administrativo pela Pontifícia Universidade Católica de Minas Gerais (PUC/MG). Graduada em Direito Pesquisadora integrante do grupo de pesquisa "Consumo e Cidadania" (CNPq). Advogada. E-mail: isabellerodrigues.adv@ gmail.com. Orcid: https://orcid.org/0000-0001-97545805
} 
Keywords: Consumer Harassment; Pregnant women; Hypervulnerability; Duty of Information; State; Suppliers.

\section{INTRODUÇÃO}

Na contemporaneidade, vislumbra-se que as relações sociais são marcadas pela celeridade. A velocidade é uma constante na vida dos indivíduos, seja para chegar em seu local de trabalho, seja para atingir seus planos de vida. A verdade é que estar parado parece um contrassenso na dinâmica atual.

Acompanhando esta lógica fugaz, efêmera, o consumo tem se apresentado como mola propulsora neste contexto. O ideal é consumir mais, de forma excessiva e volátil, afinal, o que está nas vitrines físicas e digitais hoje, não estará mais amanhã, o que evidencia um verdadeiro ciclo vicioso de consumo. A reciclagem de bens e serviços é uma necessidade artificial impulsionada pelo sistema capitalista e pela globalização.

Nesse sentido, o consumismo se faz presente por meio de estratégias manipuladoras de marketing, as quais persuadem os indivíduos a consumirem de forma irracional, com promessas de felicidade plena. A indústria cultural de massa fomenta tais práticas no intuito de consolidar o consumo artificial, irrefletido e habitual.

Tal situação agrava a vulnerabilidade do consumidor, especialmente daqueles que são hipervulneráveis, como é o caso das gestantes, as quais, devido a fatores fáticos ou socioeconômicos, técnico ou profissional, jurídico ou científico, informacional e biológico, possuem sua vulnerabilidade temporariamente agravada nos, aproximadamente, 9 meses gestacionais.

Nessa senda, é importante que o dever informacional a esse público seja capitaneado pelo Estado e pelos fornecedores, os quais devem apresentar informações claras e adequadas aos consumidores, especialmente, às gestantes, de modo que estas não façam escolhas coagidas ou direcionadas a bens de consumo supérfluos. Por tais razões, percebe-se que este grupo social deve receber tratamento jurídico diferenciado em atenção a sua condição temporária.

Logo, o objetivo do artigo é analisar algumas situações caracterizadoras do assédio de consumo na hipermodernidade, em especial, das gestantes e seu enquadramento nos grupos hipervulneráveis. A partir dessa constatação, destacar a relevância da atuação proativa do 
Estado e dos fornecedores no sentido de disponibilizarem informações claras a este segmento de modo que às gestantes sejam verdadeiramente livres para fazer as escolhas de consumo pertinentes a ela própria e ao seu filho(a).

A metodologia da pesquisa é exploratória e a abordagem é qualitativa. Procedimentalmente, foi usado o levantamento bibliográfico para abordar o tema em apreço.

$\mathrm{O}$ artigo está dividido em quatro seções. A primeira trata do assédio de consumo perpetrado pela indústria cultural de massa no contexto da hipermodernidade. Na seção seguinte, é feito o enquadramento da gestante na categoria de consumidores hipervulneráveis. A seção três discute a necessidade de atuação proativa do Estado e dos fornecedores quanto ao dever de prestar informações claras e adequadas sobre produtos e serviços, especialmente, às gestantes. Por fim, na última seção, são apresentadas as considerações finais do presente estudo, com destaque à relevância da atuação conjunta do Estado e dos fornecedores de forma a conceder subsídios para que a gestante consuma de forma autêntica, a partir de suas necessidades vitais e não, de um consumo excessivo e artificial.

\section{O ASSÉDIO DE CONSUMO NA SOCIEDADE LÍQUIDA}

O advento da "modernidade líquida" trouxe diversos impactos nas relações humanas, principalmente nas relações de consumo, consoante explana o sociólogo polonês Zygmunt Bauman.

O autor (2001) traz à tona uma metáfora acerca do sentido de fluidez advindo dos líquidos e gases, explicando que estes estão sujeitos a uma constante mudança desde que submetidos a uma tensão, o que diverge dos sólidos. Assim, os sentidos imputados a "fluidez" ou "liquidez" se mostrariam adequados para captar a natureza da fase atual, por representarem a dinâmica da sociedade contemporânea.

Ademais, Bauman (2001) registra que ser moderno significa, hoje em dia, ser incapaz de parar e, ainda menos, ficar parado. A sociedade está em constante movimento para atingir seus objetivos, cumprindo ressaltar que, por mais que o indivíduo se empenhe para atingir o horizonte da satisfação, o momento da realização da autocongratulação se move de forma extremamente rápida. A sociedade, portanto, é líquida e encontra-se em constante movimento. 
Este momento atual também é objeto de análise pelo filósofo francês Gilles Lipovetsky (2004, p. 56), o qual destaca a intensidade do presente contexto, o qual denomina de hipermodernidade: "A hipermodernidade simboliza o surgimento de uma nova modernidade, como uma espécie de 'aprimoramento' daquela vivenciada anteriormente”.

Importante ressaltar que este panorama não representa o fim da pós-modernidade, mas apenas uma versão acentuada de algumas de suas principais características. Nas palavras de Daniel Nery da Cruz (2013, p. 80): “O prefixo 'hiper’ faz menção a uma exacerbação dos valores da modernidade; é a cultura do excesso determinada e marcada pelo efêmero em que o sujeito, em ritmo frenético, busca a satisfação dos seus desejos".

O contexto atual é descrito por uma sociedade que enaltece o excesso e supérfluo, trazendo significativas mudanças aos planos de vida dos indivíduos. A valorização do presente, do hedonismo, do individualismo são notórios traços do contexto atual. Contudo, este panorama também caracterizado por diversos paradoxos, consoante explana Lipovetsky (2004, p. 27):

Eis apenas uma amostra dos paradoxos que caracterizam a hipermodernidade: quanto mais avançam as condutas responsáveis, mais aumenta a irresponsabilidade. Os indivíduos hipermodernos são ao mesmo tempo mais informados e mais desestruturados, mais adultos e mais instáveis, menos ideológicos e mais tributários das modas, mais abertos e mais influenciáveis, mais críticos e mais superficiais, mais céticos e menos profundos.

O contexto atual desperta reflexões, haja vista que, por mais que seja novo de muitas maneiras, possui traços da pós-modernidade, verificando-se, portanto, uma coexistência de dois momentos.

Todavia, é imperioso ressaltar que a força motriz que entrelaça essas duas realidades é o consumismo, fenômeno que ganha destaque neste cenário. Ressalte-se que a prática de consumir no contexto atual não se restringe às questões existenciais, pelo contrário, a hipermodernidade enfatiza planos de vida que estão diretamente relacionados a uma demanda insaciável de bens e serviços.

A felicidade passa a ser ressignificada. Não se trata mais de um mero sentimento, de algo transcendental, mas de um verdadeiro poder de compra de produtos e serviços, a partir de um estado de irracionalidade decisória. Os estudiosos Verbicaro e Soares (2017, p. 349) esclarecem o sentido que é atribuído a felicidade na sociedade hipermoderna:

O hiperconsumidor procura a felicidade não mais no "ser", e sim no "ter", e a partir do momento em que felicidade é associada a fatores exclusivamente tangíveis, o seu locus passa a ser as vitrines das lojas. Cada elemento ali exposto é, então, vislumbrado 
como um refúgio em meio ao vazio em que a hipersociedade se vê mergulhada. Assim é que a felicidade deixa de ser algo transcendental e passa a ser consumível. O prazer que o consumo proporciona transforma-se em sinônimo de felicidade, de modo que quanto mais prazer o ser humano é capaz de obter, mais "feliz" ele é. A parte se confunde com o todo, e o prazer, que antes era concebido apenas como um dos fatores propícios à felicidade, é elevado à categoria de verdadeiro arquétipo da felicidade.

$\mathrm{O}$ ato de consumir é associado ao prazer e a felicidade. Tais mensagens, expressas ou implícitas, são imediatamente direcionadas ao público, por meio de agressivas práticas de publicidade, as quais manipulam a liberdade dos consumidores, a partir da premissa de que a aquisição de bens e produtos garantem a felicidade plena do indivíduo.

Este assédio de consumo é diário e é direcionado aos mais diversos grupos sociais, pois a intenção é que o consumismo faça parte dos planos de vida e dos hábitos dos indivíduos, os quais se mostram extremamente vulneráveis, principalmente, do ponto de vista técnico. Sobre o assédio de consumo na sociedade na sociedade contemporânea, Verbicaro, Soares e Ataíde (2018, p. 169) explicam:

O assédio de consumo é caracterizado pela prática de condutas agressivas, que afetam diretamente a liberdade de escolha do consumidor e, em situações mais graves e continuadas, seus próprios projetos de vida, atentando contra a sua esfera psíquica, que, em meio a tantas estratégias manipuladoras, é subjugado e levado a ceder às pressões de mercado.

As publicidades, portanto, são as ferramentas utilizadas pela indústria cultural de massa para ganhar novos adeptos de um estilo de vida capitaneado pelo consumo excessivo. Os anúncios atrelam a felicidade àqueles que se submetem ao consumo irrefletido, além de fixar padrões de consumo e maximizar necessidade artificiais.

De acordo com Loiane Verbicaro (2018), a indústria cultural se encarrega de ditar modelos de comportamento pré-estabelecidos, definir quais serão as inéditas necessidades em âmbito global, interferir no senso estético e informar os bens que devem ser adquiridos para se que alcance o status social pretendido.

Nesse contexto, é de grande relevo mencionar que uma das formas de assédio de consumo na atualidade se dá por meio do protagonismo dos influenciadores digitais, os quais, segundo Verbicaro, Farage Filho e Montão (2020) são personalidades com capacidade de persuadir determinados grupos sociais. Assim, diversas celebridades exaltam nas redes sociais a felicidade e o prazer inerentes ao consumo superficial, assegurando aos seus seguidores, que a reprodução destes hábitos também garantirá a eles esses mesmos sentimentos. 
Torna-se nítido que as abordagens são persuasivas e múltiplas. A ideia é que os indivíduos se rendam as técnicas de manipulação, e se amoldem aos nichos pré-fabricados formados pela industrial cultural de massa. Esta submissão, que por vezes, pode parecer amena e sutil, traz impactos drásticos nos planos de vida de cada indivíduo, os quais são despidos de escolhas autênticas e são desenhados de acordo com os comandos da indústria cultural.

O consumismo se apresenta com mola propulsora deste contexto, fomentando uma verdadeira compulsão dos consumidores aos produtos e serviços culturais da sociedade industrial, além de prometer a felicidade plena, sensação de pertencimento social e cultivar o hedonismo.

Nesse viés, o consumo artificial é facilmente atrelado à felicidade, ao prazer, ao bemestar social. Contudo, a parte que é ocultada pela industrial cultural de massa e pelo sistema capitalista são os grandes malefícios advindos desse cenário, isto é, os efeitos advindos desse contexto e a fragilidade de determinados consumidores diante deste assédio de consumo.

A sociedade atual é caraterizada pela pluralidade. Cada grupo possui suas peculiaridades próprias, as quais devem ser levadas em consideração pelo ordenamento jurídico. Por tal motivo, o Código de Defesa do Consumidor apresenta em seu art. $4^{\circ}$, I, o princípio da vulnerabilidade do consumidor nas relações de consumo, no intuito de proteger a parte mais vulnerável da relação de consumo.

Nas palavras de Miragem e Bergstein (2017, p. 71):

\begin{abstract}
A vulnerabilidade do consumidor é expressamente reconhecida no contexto da Política das Relações Nacionais de Consumo por força do disposto no art. $4^{\circ}$, I. Tratase, com efeito, da aceitação que o consumidor se encontra em situação desvantajosa em relação ao seu parceiro contratual. Tal condição preterida é fruto de grande desequilíbrio existente entre o conhecimento profissional detido pelos consumidores e o oposto do desconhecimento por parte dos consumidores, os quais são sujeitos a inúmeros riscos gerados pelo desenvolvimento tecnológico e pela produção massificada.
\end{abstract}

Em que pese a previsão do princípio da vulnerabilidade, por vezes, é necessário desigualar ainda mais para que se atinja a igualdade material, logo, ainda que o consumidor goze da proteção contida no art. $4^{\circ}$, I do CDC, verifica-se que determinados grupos sociais possuem sua vulnerabilidade agravada, como é o caso das gestantes, as quais, por questões biológicas temporárias, encontram-se extremamente vulneráveis a esta abordagem manipuladora da indústria cultural de massa.

Sendo assim, passa-se à análise da condição jurídica das gestantes no contexto atual. 


\section{A VULNERABILIDADE AGRAVADA DA CONSUMIDORA GESTANTE E O ASSÉDIO DE CONSUMO}

Sendo o assédio de consumo um problema que pode atingir uma ampla quantidade de consumidores, inclusive de forma indeterminável, é preciso atentar para determinadas categorias de consumidores que são considerados mais vulneráveis que os demais, a fim de lhes possibilitar uma efetiva proteção jurídica diante desta prática mercadológica repleta de abusividades, na linguagem do Código.

Segundo o princípio da vulnerabilidade, disposto no artigo $4^{\circ}$, inciso I do Código de Defesa do Consumidor, todos os consumidores são vulneráveis nas relações de consumo. A vulnerabilidade pode ser definida como a dificuldade que o(a) consumidor(a) possui de intervir nos meios de produção do fornecedor, motivo pelo qual se torna imprescindível que este, além do Estado, lhe garanta um tratamento jurídico diferenciado.

Para além deste princípio - que também é informador da Política Nacional das Relações de Consumo -, Cláudia Lima Marques (2016) pontua que existe uma noção agravada de vulnerabilidade, a chamada hipervulnerabilidade. No mesmo sentido, Rizzato Nunes (2012) denomina de "excepcional vulnerabilidade", referindo-se àquelas categorias de consumidores que, de maneira definitiva ou temporária, encontram-se em uma situação especial.

A hipervulnerabilidade está retratada no artigo 39, inciso IV, do Código de Defesa do Consumidor (BRASIL, 1990, online), que considera como prática abusiva "prevalecer-se da fraqueza ou ignorância do consumidor, tendo em vista sua idade, saúde, conhecimento ou condição social, para impingir-lhe seus produtos ou serviços".

Ao prosseguir na temática, a professora Cláudia Lima Marques delimita algumas categorias de consumidores que podem ser considerados hipervulneráveis, quais sejam: as crianças, os idosos, pessoas com deficiência, portadores de certas doenças crônicas, analfabetos e as gestantes.

Sob um olhar atento à categoria das consumidoras gestantes, que, durante 09 meses, sofrem a incidência de inúmeras transformações fisiológicas, emocionais, psíquicas e comportamentais, nota-se que, apesar de se tratar de uma vulnerabilidade temporariamente 
agravada, precisam de um tratamento jurídico-material diferenciado, preservando-se a sua saúde, segurança e dignidade nas relações de consumo (NADAI; SILVEIRA, 2016).

Cláudia Lima Marques costuma dividir o conceito de vulnerabilidade em: i) fática ou socioeconômica; ii) técnica ou profissional; iii) jurídica ou científica e iv) informacional (MARQUES apud XAVIER; RIEMENSCHNEIDER, 2019). A vulnerabilidade costuma ser analisada tão somente sob um ou dois enfoques. Na situação da consumidora gestante, muitos ou todos os aspectos podem estar presentes, enquadrando-lhe, sem dúvidas, na categoria de consumidora hipervulnerável, sendo esta hipervulnerabilidade de caráter temporário ou situacional (XAVIER; RIEMENSCHNEIDER, 2019).

No aspecto fático ou socioeconômico, existem especificidades inerentes às transformações fisiológicas naturais e inerentes tanto ao período gestacional quanto logo após o parto - período conhecido como puerpério, que reflete as inúmeras alterações hormonais e psíquicas. Portanto, a consumidora gestante está, biologicamente falando, mais vulnerável ao assédio de consumo.

Ao analisar o aspecto técnico ou profissional juntamente do aspecto econômico, é preciso atentar para o fato de que, historicamente, no tocante à produção de bens e serviços e movimentação da economia, as mulheres sempre foram tratadas como uma categoria secundária em relação aos homens.

No Brasil, a Pesquisa Nacional por Amostra de Domicílios Contínua (PNAD Contínua), realizada pelo Instituto Brasileiro de Geografia e Estatística (IBGE) e divulgada em 2019, demonstra que as mulheres ganham uma média de 20,5\% menos que os homens (PARADELLA, 2019). Somado a isto, também é comum que as mulheres sejam demitidas logo após o retorno da licença-maternidade - respeitando-se ou não o período de estabilidade provisória garantido na legislação trabalhista -, colocando-as, muitas vezes, em uma situação de afastamento do mercado de trabalho (BATISTA, 2019).

$\mathrm{Na}$ contramão disto, o mercado de consumo evoca outra perspectiva, mirando a consumidora gestante como um público-alvo promissor de diversos segmentos empresariais: desde a alimentação, vestuário, eventos sociais, enxovais, até planos de saúde e medicamentos, por exemplo.

Acerca do fator jurídico ou científico da hipervulnerabilidade, analisando-se juntamente do aspecto informacional, tem-se que, a depender do estrato social considerado, do 
nível de escolaridade e da quantidade de filhos, a gestante pode estar ainda mais exposta às práticas abusivas dos fornecedores nas relações de consumo - muitas que ela sequer saberia identificar como antijurídicas, a exemplo do assédio de consumo.

Nota-se, portanto, com evidência, que a gestante, enquanto consumidora, tem a sua vulnerabilidade agravada em diversas perspectivas, devendo ser conferido a ela um tratamento diferenciado no tocante às relações de consumo, a fim de ampliar sua proteção jurídica diante de possíveis violações, ou mesmo para evitá-las.

Uma das situações nas quais as consumidoras gestantes estão expostas é o assédio de consumo, que, na atualidade, vem ocorrendo com muita facilidade no ambiente digital, tema que merece atenção.

Os artigos 29 a 37 do Código de Defesa do Consumidor (BRASIL, 1990) preveem algumas práticas abusivas em relação ao âmbito pré-contratual das relações de consumo. As práticas caracterizadoras do assédio de consumo se expressam de várias formas, dentre elas a publicidade que omite informações essenciais de que o consumidor deveria ter conhecimento acerca do produto ou serviço que está adquirindo, conforme o parágrafo $3^{\circ}$ do art. 37 .

Ainda, há as modalidades de publicidade enganosa ou abusiva, conforme descrito pelos parágrafos $1^{\circ}$ e $2^{\circ}$ do mesmo artigo, respectivamente. Nos termos do parágrafo $1^{\circ}$, por exemplo, pode haver a

[...] criação de falsas necessidades de consumo, tudo, em prejuízo da livre manifestação de vontade do consumidor, frustrando sua expectativa quanto ao conteúdo da informação ali contida, prática essa que, quando veiculada por um meio de comunicação em massa, recebe a pecha de oferta publicitária enganosa [...] (VERBICARO; RODRIGUES; ATAÍDE, 2018, p. 172).

Dessa forma, é possível constatar que as consumidoras gestantes são vistas como um grande público-alvo dos mais diversos segmentos do mercado, tendo em vista que o período gestacional marca a transição para uma nova fase de consumo: deste momento em diante, passa a existir a necessidade de consumo por dois: pela mãe e pelo bebê, perpassando por toda a infância e adolescência do filho(a), até atingir a idade produtiva e ter condições de prover o seu próprio sustento.

Grande parte dos apelos publicitários direcionados às gestantes objetivam o estímulo ao consumo por meio da emoção, utilizando estratégias específicas de marketing - como o 
neuromarketing ${ }^{3}$ - que tendem a envolvê-las de forma a facilitar o consumo irrefletido, gerando o agravamento de uma vulnerabilidade psicológica. Nesta linha de raciocínio, Davies et al. e Rothman (apud NADAI; SILVEIRA, 2016, p. 299) entendem que:

[...] as ações de marketing podem intensificar a experiência da vulnerabilidade da gestante, uma vez que constroem crenças sobre a idealização da maternidade, principalmente quando relacionadas ao consumo de serviços específicos e que demandam extrema confiança, como é o caso dos serviços médicos. [...] O excesso de informações e a pressão imposta pela conduta de como ser uma 'boa mãe' causam estresse e angústia. Ao analisar os esforços de marketing voltados para este segmento de mercado, o fator primordial é entender se essas consumidoras possuem discernimento suficiente para compreender este processo como algo construído e com o qual elas estão habituadas a lidar ou se de alguma forma, em decorrência do seu estado emocional transitório, elas sentem certa imposição ou até mesmo vulnerabilidade em relação às exigências do mercado?

$\mathrm{O}$ assédio de consumo direcionado às gestantes pode desencadear a aquisição de produtos e serviços prejudiciais à saúde e segurança da própria gestante e da criança que está sendo gerada, envolvendo até mesmo os aspectos psíquico e emocional. Elas passam a ser bombardeadas por estímulos ao consumo desde os primeiros momentos de descoberta da gravidez, inclusive sobre itens que não são necessários, mas que se cria uma expectativa de que será útil ou transmitirá praticidade para a consumidora gestante.

Neste particular, há, inclusive, o estímulo ao consumo de determinados alimentos e medicamentos, difundindo-se até mesmo por alguns profissionais da saúde mais conhecidos. Como exemplo, ressalta-se a discussão sobre o aleitamento materno industrializado (XAVIER; RIEMENSCHNEIDER, 2019), cuja indústria fomenta o consumo do leite artificial e outros suplementos em detrimento do leite natural, a partir da ideia de que é um substituto perfeito do leite natural - contrariando a recomendação da Organização Mundial da Saúde (BRASIL, 2020).

Ainda sobre as questões relacionadas à saúde, alerta-se para a oferta e publicidade abusivas dos contratos de planos e seguros privados de saúde que podem ser praticados contra a gestante, incidindo-se a Lei n. 9.656 de 1998.

\footnotetext{
3 "O neuromarketing surge para obtenção de um maior arcabouço de conhecimento, com a proposta de agregar às informações comportamentais as motivações ocultas no inconsciente da mente que direcionam os indivíduos em seu processo de escolha. Surge, portanto, no intuito de melhorar a elaboração de ofertas de valor para o cliente ou consumidor e utiliza e aplica métodos da neurociência e suas ferramentas para seu diagnóstico". Cf. COLAFERRO, Claudia Almeida; CRESCITELLI, Edson. A Contribuição do Neuromarketing para o Estudo do Comportamento do Consumidor. Brazilian Business Review, v.11, n.3, Vitória-ES, Maio-Jun. 2014, p. 130-153. Disponível em: https://www.redalyc.org/pdf/1230/123031118006.pdf. Acesso em: 10/03/2020.
} 
Também no ambiente digital, notadamente nas redes sociais, há diversos estímulos ao consumo por meio do marketing de influência, alcançando, principalmente, as consumidoras que não conseguem discernir se se trata de um "post patrocinado" ou um relato real de experiência. São atos que, normalmente, são captados a partir de um estímulo em massa nas redes sociais que, quando praticados, também passam a ser registrados espontaneamente, gerando um ciclo quase infinito de compartilhamentos.

A situação também se agrava em relação às gestações não planejadas, tratando-se de um orçamento familiar que teve de ser reorganizado às pressas. São nestas situações que se consegue notar com maior evidência o lado sombrio do assédio de consumo, que atinge pessoas de distintas classes sociais, prejudicando-as em maior ou menor medida.

Perpassando-se por diversos segmentos do mercado, desde a alimentação, vestuário, festas infantis, enxoval, planos de saúde, até medicamentos, dentre outros, inclusive no ambiente virtual, principalmente nas redes sociais, a maternidade é um período especial vivenciado por algumas mulheres, e, como tal, deve ser objeto de estudo e proteção pelo Direito do Consumidor, para que, a partir de um desequilíbrio fático-jurídico ainda maior percebido nas relações de consumo, as consumidoras gestantes consigam obter a prevenção e reparação pelos danos decorrentes do assédio de consumo.

\section{DEVERES DO ESTADO E DOS FORNECEDORES E O DIREITO À INFORMAÇÃO COMO CONDIÇÃO EMANCIPATÓRIA DAS GESTANTES}

Além do assédio de consumo praticado por uma publicidade direcionada, o assédio de consumo digital também pode ocorrer de maneira difusa, direcionado a uma ampla quantidade de gestantes, até mesmo de maneira indeterminada. Neste aspecto, torna-se importante que o Estado cumpra com seu papel delineado pela Política Nacional das Relações de Consumo, mormente no artigo $4^{\circ}$ do Código de Defesa do Consumidor. Esta Política foi construída exatamente com o objetivo de

[...] disciplinar o comportamento do Estado como grande mediador de interesses contrapostos da sociedade de consumo e dos agentes do mercado, concretizando o princípio da harmonia das relações de consumo de relevo constitucional pela compatibilização da livre iniciativa e da proteção do consumidor como pilares da ordem econômica, nos termos do artigo 170, caput e seu inciso V da Constituição Federal (VERBICARO, 2018, p. 28). 
Na prática, observa-se que, muitas vezes, o Estado não cumpre seu papel de mediador qualificado das relações de consumo, sendo um dos motivos para que se considere haver uma vulnerabilidade agravada das consumidoras gestantes, que assumem uma posição ainda mais desequilibrada no mercado de consumo.

Ao Estado caberia não apenas o papel fiscalizatório e fomentador de um desejado equilíbrio entre fornecedores e consumidores, mas também o papel de elevar o nível jurídicoinformacional das gestantes, para que, juntas, consigam reconhecer as violações - que, por vezes, ocorrem de maneira sutil - e, bem assim, para que consigam alcançar uma emancipação social por meio de associações, por exemplo, no escopo de combate aos danos decorrentes do assédio de consumo no ambiente virtual.

Trata-se de um efetivo direito à informação, que, não apenas deve ser promovido pelo Estado, mas também pelos fornecedores, que deveriam promover uma publicidade não assediadora, tampouco estimuladora de hábitos de consumo que podem levar não só ao endividamento, mas também a prejuízos à saúde e segurança da gestante e da criança.

Nesse sentido, Miragem e Bergstein (2018) esclarecem que existe uma delimitação mínima obrigatória da informação ao consumidor que possui um maior grau de vulnerabilidade, para que esta seja realmente considerada adequada em relação a norma contida no art. 31 do CDC. Logo, afastando-se da criação de falsas necessidades, as informações prestadas acerca de alimentação, vestuário, planos de saúde, dentre outros, devem guardar total correspondência com a realidade das consumidoras gestantes.

Assim, é importante destacar que o Estado e os fornecedores possuem responsabilidade conjunta na divulgação de informações claras, adequadas e qualificada a todos consumidores, especialmente, aos hipervulneráveis, como é o caso das gestantes. É de fundamental importância os fornecedores atuem de forma proativa no fornecimento de informações e que o Estado estimule o consumo consciente.

Afinal, munidas das informações científicas e jurídicas necessárias, as gestantes podem buscar uma tutela mais ampla, a fim de prevenir novas condutas assediadoras, em especial no meio digital. É indiscutível que as consumidoras gestantes merecem especial tratamento pelas esferas públicas e privadas, no tocante às relações de consumo, considerando 
a sua condição fisiológica diferenciada - e, muitas vezes, informacional e econômica - bem como em atenção aos seus direitos fundamentais.

Dessa forma, as gestantes terão plenas condições de fazer escolhas racionais, baseadas em questões existenciais, garantindo, assim, sua emancipação. Não se pode olvidar que todos devem ser livres verdadeiramente livres para tomar suas decisões, especialmente, no que tange ao seu bem-estar e de seus familiares.

\section{CONSIDERAÇÕES FINAIS}

Considerando o panorama atual, caracterizado pelo consumo ostensivo e superficial, percebe-se que a industrial cultural de massa vem ditando comportamentos, por meio das redes sociais, dos digital influencers e das mais variadas técnicas publicitárias, inclusive, do neuromarketing.

Ocorre que estas práticas manipuladoras enaltecem determinados modos de vida que supostamente assegurariam prazer e felicidade, baseados no consumismo. Diariamente, são criadas novas necessidades de consumo, as quais são inesgotáveis e efêmeras.

Contudo, a vulnerabilidade dos consumidores já prevista no Código do Consumidor é agravada neste contexto de assédio de consumo, logo, determinados grupos sociais necessitam ter uma maior proteção jurídica, como é o caso das consumidoras gestantes.

Este núcleo social, devido a fatores biológicos temporários, que resultam em diversas transformações fisiológicas, emocionais, psíquicas e comportamentais, são mais vulneráveis ao assédio de consumo perpetrado pela indústria cultural de massa e por tão razão merecem uma proteção jurídica diferenciada.

Diante deste cenário, se faz imprescindível a atuação proativa e conjunta do Estado e dos fornecedores de bens e serviços quanto ao dever informacional a todos os consumidores, especialmente, às gestantes. É essencial que, de posse de informações claras e adequadas, as grávidas, além da possibilidade de criar associações no intuito de proteger e informar outras gestantes, possam fazer suas escolhas de forma autêntica, de acordo com suas reais necessidades.

Portanto, se faz necessária a elevação do nível jurídico-informacional das gestantes por meio de ação estatal e dos fornecedores de mercadorias e serviços, em observância à Política 
Nacional das Relações de Consumo constante no Código de Defesa do Consumidor, para que, a partir disso, possam usufruir dos benefícios de um consumo consciente, refletido, que atenda às necessidades vitais suas e de seu filho(a). A liberdade de escolha da gestante deve ser prestigiada em detrimento das estratégias de manipulação da indústria cultural de massa, como forma de alcançar sua emancipação no mercado de consumo.

\section{REFERÊNCIAS}

BATISTA, Vera. Metade das mulheres grávidas são demitidas na volta da licença-maternidade. Correio Braziliense. Brasília, 12 maio 2019. Disponível em: https://www.correiobraziliense.com.br/app/noticia/economia/2019/05/12/internas_economia,7 54492/metade-das-mulheres-gravidas-sao-demitidas-na-volta-da-licenca-materni.shtml. Acesso em: 10 mar. 2020.

BAUMAN, Zygmunt. Confiança e medo na cidade. Edição digital, 2012. ISBN: 978-85-3780943-3. Disponível

em: <https://edisciplinas.usp.br/pluginfile.php/4561096/mod_resource/content/1/Confianca\%20e \%20Medo\%20na\%20Cidade\%20-\%20Zygmunt\%20Bauman.pdf >. Acesso em: 05 jun. 2020.

. Modernidade líquida. Rio de Janeiro: Zahar, 2001.

. Vida a crédito. Rio de Janeiro: Zahar, 2010.

. Vida para consumo: a transformação das pessoas em mercadorias. Rio de Janeiro: Zahar, 2008.

BUCCI, Maria Paula Dallari (Org.). Políticas públicas: reflexões sobre o conceito jurídico. São Paulo: Saraiva, 2006.

BRASIL. Lei $n^{0}$ 8.078, de 11 de setembro de 1990. Dispõe sobre a proteção do consumidor e dá outras providências. Disponível em: http://www.planalto.gov.br/ccivil_03/leis/18078.htm. Acesso em: 10 dez. 2018.

. Lei n. 9.656, de 1998. Dispõe sobre os planos e seguros privados de assistência à saúde. Disponível em: http://www.planalto.gov.br/ccivil_03/leis/L9656compilado.htm. Acesso em: 10 mar. 2020.

. Ministério da Saúde. Gravidez: o que é, sintomas, complicações, tipos e prevenção. Disponível em: https://www.saude.gov.br/saude-de-a-z/gravidez. Acesso em: 10 mar. 2020.

Nações Unidas. Ministério da Saúde lança nova campanha de incentivo à amamentação. Disponível em: https://nacoesunidas.org/ministerio-da-saude-lanca-novacampanha-de-incentivo-a-amamentacao/. Acesso em: 10 mar. 2020. 
CAMPELLO, Cynthia; VERBICARO, Dennis; MARANHÃO, Ney. Necessidades artificiais de consumo e agravamento da vulnerabilidade obreira: análise à luz do capitalismo predatório e da indústria cultural. Revista de Direito do Trabalho. Vol. 211/2020, 2020. Disponível em: <https://www.researchgate.net/publication/341903191_NECESSIDADES_ARTIFICIAIS_D E_CONSUMO_E_AGRAVAMENTO_DA_VULNERABILIDADE_OBREIRA_ANALISE_ A_LUZ_DO_CAPITALISMO_PREDATORIO_E_DA_INDUSTRIA_CULTURAL.> Acesso em 09 jun. 2020.

CEPAL: crise por causa de covid-19 será uma das piores do mundo. Agência Brasil. Brasília, 20 março 2020. Economia. Disponível em: https://agenciabrasil.ebc.com.br/economia/noticia/2020-03/cepal-crise-por-causa-de-covid19-sera-uma-das-piores-do-mundo. Acesso em: 22 abr. 2020.

COLAFERRO, Claudia Almeida; CRESCITELLI, Edson. A Contribuição do Neuromarketing para o Estudo do Comportamento do Consumidor. Brazilian Business Review, v.11, n.3, Vitória-ES, Maio-Jun. 2014, p. 130 - 153. ISSN 1807-734X. Disponível em: https://www.redalyc.org/pdf/1230/123031118006.pdf. Acesso em: 10 mar. 2020.

CRUZ, Daniel Nery da. Algumas características da pós-modernidade na concepção de Gilles Lipovetsky. Revista intuitio, v. 6, n. 1. Porto Alegre, 2013. p. 79-95.

LIPOVETSKY, Gilles. A felicidade paradoxal: ensaio sobre a sociedade do hiperconsumo. São Paulo: Companhia das Letras, 2007.

Os tempos hipermodernos. São Paulo: Barcarolla, 2004.

MARQUES, Cláudia Lima. Algumas considerações sobre a pessoa no mercado e a proteção dos vulneráveis no direito privado brasileiro. In: Direito privado, constituição e fronteiras: encontro da associação luso-alemã de juristas no Brasil. $2^{a}$ ed., São Paulo: São Paulo: Revista dos Tribunais, 2014, p. 287-332.

Contratos no Código de Defesa do Consumidor: o novo regime das relações contratuais. 8. ed. rev., atual. e ampl. São Paulo: Revista dos Tribunais, 2016.

; MIRAGEM, Bruno. O novo direito privado e a proteção dos vulneráveis. São Paulo: Editora dos Tribunais, 2014.

MERCÊS, Bruna Letícia Santos; MARTINS, Fernanda Meirelles. A hipervulnerabilidade da gestante nos serviços prestados pelos operadores dos planos de saúde. In: SANTOS, Corina Teresa Costa Rosa; PIMENTEL, Diego Ferreira; SILVA, Rômulo Ruan Santos da (Org.). Direito do consumidor aplicado ao direito à saúde: análise de julgados. Feira de Santana: Universidade Estadual de Feira de Santana, 2017.

MIRAGEM, Bruno; BERGSTEIN, Lais. O papel da informação nos contratos de consumo como modelo do Novo Direito privado solidário. In: VERBICARO, Dennis; ATAÍDE, Camila; 
ACIOLI, Carlos. Provocações contemporâneas no direito do consumidor. Rio de Janeiro: Editora Lumen Juris, 2018.

MORIN, Edgar. A via para o futuro da humanidade. Rio de Janeiro: Bertrand Brasil, 2013.

NADAI, Priscila de; SILVEIRA, Natani. Maternidade contemporânea: um estudo exploratório sobre vulnerabilidade e consumo. Revista Foco, 2016, v. 9, n. 1. Disponível em: http://www.revistafocoadm.org/index.php/foco/article/view/277/153. Acesso em: 23 dez. 2018.

NUNES, Luis Antonio Rizzatto. Curso de direito do consumidor. 7 ed. rev. e atual. São Paulo: Saraiva, 2012.

PARADELLA, Rodrigo. Diferença cai em sete anos, mas mulheres ainda ganham 20,5\% menos que homens. IBGE. Estatísticas sociais, 08 mar. 2019. Disponível em: https://agenciadenoticias.ibge.gov.br/agencia-noticias/2012-agencia-de-

noticias/noticias/23924-diferenca-cai-em-sete-anos-mas-mulheres-ainda-ganham-20-5menos-que-homens. Acesso em: 09 set. 2020.

PASOLD, Cesar Luiz. Metodologia da Pesquisa Jurídica: Teoria e Prática. 12 ed. São Paulo: Conceito Editorial, 2011.

PIERRI, Deborah. Politicas públicas e privadas em prol dos consumidores hipervulneráveis - idosos e deficientes. Revista de Direito do Consumidor, vol. 92/2014, p. 221-298, mar.-abr., 2014.

RODRIGUES, Isabelle de Assunção. O assédio de consumo no ambiente virtual diante da hipervulnerabilidade da gestante. In: VERBICARO, Dennis; VERBICARO, Loiane; VIEIRA, Janaína. Direito do Consumidor Digital. Rio de Janeiro: Editora Lumen Juris, 2020.

SCHMITTI, Cristiano Heineck. A "hipervulnerabilidade" como desafio do consumidor idoso no mercado de consumo. Revista Eletrônica da Faculdade de Direito da Universidade Federal de Pelotas (UFPel). Dossiê Consumo e Vulnerabilidade: a proteção jurídica dos consumidores no século XXI. Vol. 03, n. 1, jan-jun, 2017.

VERBICARO, Dennis. A construção de um novo modelo de cidadania participativa do consumidor a partir da Política Nacional Das Relações De Consumo. Revista de Direito do Consumidor. São Paulo, ano 26, vol. 110, março-abril/2017.

; FARAGE FILHO, Daniel; MONTÃO, Vanessa Maria Dias. As inquietações envolvendo a privacidade virtual e os dados pessoais na era dos influenciadores digitais. In: VERBICARO, Dennis; VERBICARO, Loiane; VIEIRA, Janaína. Direito do Consumidor Digital. Rio de Janeiro: Editora Lumen Juris, 2020.

; ALCÂNTARA, Ana Beatriz Quintas Santiago de. A percepção do sexismo face à cultura do consumo e a hipervulnerabilidade da mulher no âmbito do assédio discriminatório de gênero. Revista Pensamento Jurídico - São Paulo - Vol. 11, No 1, jan./jun. 2017. 
Disponível

em:

http://fadisp.com.br/revista/ojs/index.php/pensamentojuridico/article/view/81/133. Acesso em: 23 dez. 2018.

; SOARES, Lays. Reflexões sobre o consumo da hipermodernidade: o diagnóstico de uma sociedade confessional. Revista Direito em debate. Unijuí. 2017, p. 342-363.

; ___ ATAÍDE, Camille. Desvendando a vulnerabilidade comportamental do consumidor: uma análise jurídico-psicológica do assédio de consumo. In: VERBICARO, Dennis; ATAÍDE, Camila; ACIOLI, Carlos. Provocações contemporâneas no direito do consumidor. Rio de Janeiro: Editora Lumen Juris, 2018.

O desencantamento com o estado na proteção dos consumidores e a repactuação dos compromissos políticos da sociedade civil através da política nacional das relações de consumo. In: VERBICARO, Dennis; ATAÍDE, Camille; ACIOLI, Carlos (Coord.). Provocações contemporâneas no direito do consumidor. Rio de Janeiro: Lumen Juris, 2018, p. 23-59.

VERBICARO, Loiane Prado. O impacto da sociedade de massas no consumo e na ideia de cultura. In: VERBICARO, Dennis; ATAÍDE, Camila; ACIOLI, Carlos. Provocações contemporâneas no direito do consumidor. Rio de Janeiro: Editora Lumen Juris, 2018.

XAVIER, José Tadeu; RIEMENSCHNEIDER, Patrícia. A vulnerabilidade agravada do consumidor nas situações relacionadas à maternidade. Revista de Direito do Consumidor, Vol. 121/2019. Jan-fev/ 2019. 